\title{
Methods for undertaking research on technology with older and disabled people
}

\author{
Helen Petrie ${ }^{1}$, Blaithin Gallagher ${ }^{2}$ and Jenny Darzentas ${ }^{3}$ \\ ${ }^{1}$ Human-Computer Interaction Research Group, University of York, United Kingdom \\ ${ }^{2}$ National Council for the Blind, Dublin, Ireland \\ ${ }^{3}$ Department of Product and Systems Design Engineering, University of the Aegean, Syros \\ Greece \\ Helen.Petrie@york.ac.uk,blaithing@gmail.com, jennyd@aegean.gr
}

\begin{abstract}
Developing interactive systems for disabled and older people is an increasingly important topic in HCI, yet there is little discussion of methods used to conduct research with these user groups. The workshop will provide an opportunity for researchers and practitioners to discuss research methods used in HCI when applied to working with older and disabled people for the elicitation of user needs, evaluation of technologies and understanding of the uses of technologies by these important user groups.
\end{abstract}

\section{Introduction}

Developing interactive systems for people with disabilities and older people is becoming an important topic within HCI research and practice. As the population is aging [1], the pressure to use technology to support people to live independently is increasing. But as yet, little attention has been paid to the methods used to conduct research on mainstream or assistive technologies for disabled or older people. A small number of published papers directly address these issues [e.g. 2, 3] and some papers mention challenges of working with these user groups in passing.

\section{Objectives and Topics to be Addressed in the Workshop}

The workshop will provide an opportunity for researchers and practitioners to discuss the advantages and disadvantages of existing research methods used in HCI when applied to working with older and disabled people for the elicitation of user needs, evaluation of technologies and understanding of the uses of technologies by these important user groups. It will also provide an opportunity to discuss innovations to methods and completely new methods that might have been developed in working with older and disabled people.

Topics to be addressed will include: advantages and disadvantages of methods of undertaking research on technology with older and disabled people, for mainstream or assistive technologies; practical problems of using existing methods; adaptations that 
need to be made for particular user groups; limitations in the application of particular methods; innovations in research methods to meet the requirements of particular user groups and innovative research methods; theories and application of inclusive design, design for all and universal design philosophies. Finally, the workshop is open to discussion of all methods, whether qualitative or quantitative, from participatory design to experimentation, and will include inclusive design approaches.

\section{Organizers}

This Workshop is organized on behalf of IFIP WG 13.3 HCI and Disabilities by:

Helen Petrie, Professor of HCI at the University of York and current chair of IFIP WG 13.3. Her research focuses on the design and evaluation of technology for disabled and older people. Dr Blaithin Gallagher, Head of Research and Projects at NCBI. She is Vice President of the European Network for Vision Impairment Training Education and Research (ENVITER) and on the Executive Committee of the European Society for Low vision Research and Rehabilitation (ESLRR). Dr Jenny Darzentas from the University of the Aegean. Her research focuses on the design of accessible and usable content.

\section{$4 \quad$ Target audience}

Researchers and practitioners interested in working with disabled or older people in the design and development of mainstream or assistive technologies.

\section{$5 \quad$ Expected outcomes}

The workshop will contribute to the development of a better understanding of research methods for working with older and disabled people. In addition, the workshop will plan for further events, including a tutorial for new researchers in the field and a handbook on methods for working with older and disabled people.

\section{$6 \quad$ References}

1. Giannakouris, K.: Ageing characterizes the demographic perspectives of the European societies. Eurostat Statistics in focus 72. Luxembourg: Eurostat. (2008).

2. Hendriks, N., Huybrechts, L., Wilkinson, A. Slegers, K.: Challenges in doing participatory design with people with dementia. Proceedings of the 13th Participatory Design Conference: Volume 2 (pp. 33-36). Windhoek, Namibia: ACM (2014).

3. Inglis, E. A., Szymkowiak, A., Gregor, P., Newell, A. F., Hine, N., Shah, P., Wilson, B.A., Evans, J.: Issues surrounding the user-centred development of a new interactive memory aid. Universal Access in the Information Society, 2(3), 226-234 (2003). 